\title{
How Managers Conceive the Idea of Creativity: An Empirical Research
}

\author{
Rosella Tomassoni, Eugenia Treglia, Silvia Perrella
}

\begin{abstract}
The research aims to explore the concepts related to creativity and managerial practices connected with it in a sample of managers. The survey also aims to a deepening of the concept of creativity in human resources management. The qualitative study was conducted by laying out a sample of a direct interview with open questions, addressed to managers of companies, organizations and associations. The results confirm the important role of the Manager, of the Human Resources and of their "creative management" in the evolutionary process toward the new and useful, that daily involved the business organization.
\end{abstract}

\section{INTRODUCTION}

A "creative mind" allows you to generate ideas, to solve and anticipate potential problems, to turn insights into ideas and solutions that can help the achievement of the objectives that we have set ourselves. Creativity is "the art to define problems and suggest appropriate solutions" (Joly, 1995); it is "the ability to produce new ideas to create value" by identifying original ways to take advantage of opportunities (Florida, 2003).

It can result from "an attitude or a decision, either explicit or implicit, to exercise control over reality in order to change it" (Jaoui, 2003); therefore, the "creative practice" allows us to develop and effectively use our ability to find original and acceptable solutions; "creativity, in its ordinary expression, often appears as the search for a new approach to a problem, however familiar" (Goleman, 1999). Creativity is "the ability to think outside a specific scheme and reach new and functional conclusions, apt to solve a problem or seize an opportunity" (Bertone, 2003); it can be classified as "a soft skill" to add to the "traditional management skills".

Creativity is an "innate resource" for everybody, a "gift" to cherish in everyday life, particularly in one's workplace. First of all it is essential to become "fully" aware" of our "creative potential" as individuals, defying inner and external difficulties (Gurteen, 1998), and then transfer this "valuable tool" into the collective and organizational fields; creativity is sometimes perceived as "specialized" and applicable only in certain corporate areas. "In the role of the manager there is an educational mission as a guide. It is up to the management to create a dialectic climate and a favorable atmosphere to the emergence of creative proposals by encouraging autonomy and initiative" (Jaoui - Dell'Aquila, 2008). For these promoters it is important that employees' ideas are welcomed and appreciated, because "a good manager is one who discovers in each collaborator the specific factors that motivate him to direct them towards the business objectives" and "the challenge for managers is to build and manage contexts that can favour the development of ideas, focusing mainly on business creativity ". The "creative manager" manages to combine planning with change, the rule with the unexpected event, turning to his advantage every situation apparently unfavourable.

Teresa Amabile (1998) has identified the so-called "killers" of creativity, emphasizing the importance of the "manager's role" to promote creativity also in traditional contexts; she defines creativity as the combination of experience and knowledge in a specific field, as the ability to watch events from a new perspective by imagining a wider spectrum of possibilities as inner drives coming from one's pleasure and passion. She argues that the use of "the creativity techniques", together with the "management practices", may help to develop" the creative potential of human resources." We have to entrust collaborators and projects with tasks that agree their best, by giving them autonomy in achieving the goals that must comply with the strategy of the company.

Salvatore Vicari (1998) defines creativity in organizations as "the result of the conditions in which there is the whole organization, underlying the importance of relational and social context in which 
they work as individuals. The organizational creativity is the environment, the context in which innovative processes can be developed more easily. The author argues that creativity is the input while innovation is the output. In the presence of a high environmental complexity and a high level of business competitiveness, the success of the organization is related to the ability of the manager to build and create new models through a "creative management". Creativity plays a key role in generating ideas; innovation turns those ideas into action through selection, improvement and implementation (Gurteen, 1998). One of the major problems is the ability of companies to create a cultural and organizational context suitable to the development of innovative ideas, and the readiness for a new and effective experimentation, in search of the necessary balance between rationality and creativity (Varra, 2012). Creativity is a crucial resource, which may lead to an idea of developing and implementing in a business plan. It can allow a company to reinvent itself in a new business or even simply and correctly interpret the market dynamics, and, more generally the external environment it must constantly face. Creativity can ease the process of renewal and growth even in more traditional sectors favouring an evolutionary and improving trend; it is therefore appropriate to cultivate and develop the creative potential of human resources (Thompson, 2013), with the use of creativity techniques (Gianandrea 2009, Osborn 2003) of lateral thinking (De Bono, 2000), the dimension of play, fantasy and imagination. In recent decades, interest in creativity has increased considerably thanks to the impulse of major changes in the economic and social scenarios, which stimulate flexible attitudes and needs of innovation (Legrenzi, 2005), original ideas and more effective processes. Hence the importance of studying the creative power in the actual practice of Organizations", whose central role is the well-being and the development of Human Resources. The common result attained, despite the diversity of disciplinary approaches, can be summarized as follows: 1) There are organizational and motivational factors (business climate, leadership style, corporate culture, resources and skills, intrinsic motivation etc.) favouring and stimulating the "creative process"; 2)The importance of the role of "the manager" (Agnesa, 2012), as a facilitator and promoter of a "creative management" of the organization; 3)Training for the use and development of creativity through the practice of continuous and systematic "Creativity Techniques" (De Bono 2012, Buzan 1996 Raudsepp 1989).By combining the above mentioned variables society can reach a "creative management" of human resources aimed at finding out new ideas and solutions that can be implemented in innovation.

\section{AIM OF THE RESEARCH}

The research aims to explore the concepts related to creativity and managerial practices connected with it in a sample of managers. The survey also aims to a deepening of the concept of creativity in human resources management, starting from the contextualization of the creative process in the individual examined and from the analysis of internal and external variables that can stimulate the creative potential, the opportunities and the critical points that may result and the spread of the Techniques of Creativity. The study is therefore aimed at the collection of a practical experiential contribution that, considering the specificity of the "creative process", can provide additional insights for a more fruitful implementation of theoretical contributions to the business operational practice.

\section{Methodology}

Starting from the theoretical patterns (Jaoui 2008, Bertone 2003, Amabile 1998, Vicari 1998), which highlighted the importance of the manager's role in encouraging the "creative process" in organizations, we have analyzed the issue in terms of perception and sensitivity management by highlighting the main implications about the management issues regarding Human Resources. This topic has been dealt with by interviewing "the managers", leading figures in the management, who can stimulate the factors and the upstream process of the innovations and transformations adopted, that is the promoters" of the best combination of human, technical and financial resources (Goi, 2014).

\section{INSTRUMENTS}

The qualitative study was conducted by laying out a sample of a direct interview with open questions (a total of twelve questions), addressed to managers of companies, organizations and associations, in two Italian regions, Lazio and Puglia. The interviews were conducted over a period of six months. Technically, the choice of the open questions was suggested by the peculiarities of the subject under investigation and has revealed the originality and sensitivity as regards the deepening of the argument by the respondents that probably would have remained unexplored if the closed question system, 
aseptic and impersonal had been adopted. The questions in the interview aim at the building of a process of analysis that, drawing inspiration from the definition of creativity developed by the French mathematician Henri Poincaré (in particular as regards the novelty / utility binomial), leads the interviewee to contextualize the concept within its own organizational reality, highlighting present specific and characteristic elements, through the description of experiences particularly significant and emblematic. The speech that so easily develops deals with the issue of internal and external factors that can promote or conversely inhibit the creative process and its benefits, opportunities and difficulties (if any) of a creative management approach. Special attention was given to organizational factors in human resource management, such as team work, the diversity of skills, knowledge and information sharing, collaboration or competition among employees, inner motivation and organizational well-being, the experimentation of a new thinking out of the scheme. Finally, we've tackled the issue of training of human resources through the techniques of creativity, and how creativity can be considered as a "shared value" and an integral part of a corporate culture. The contributions were then collected into a single summary document which became a photograph of the organizational realities involved, explaining the perception of the concept of creativity and its importance in the management and development of organizations.

\section{The SAMPLE}

The organizations involved are characterized by the heterogeneity of the sector and a consolidated presence in the territory. The selected sample, including fifteen organizational realities, is therefore highly varied in relation to the core business: these are companies operating in different sectors (Information Communication Technology, Contacts and Call Centre Services, Business Services, Customer Care and Direct Marketing, Environmental services, Health private, organizational Consulting Management and business training, asset management), Ministry of Defence (Inspectorate General of Military Health), University of Cassino (Area Executive Student Services), Bari Polytechnic (Department of Electrical and Information Engineering), business associations (Confimpreseitalia, Consortium for Industrial Development in Southern Lazio).

In particular:

1. Exprivia Healthcare IT Srl - President and CEO

2. Exprivia Projects Srl - CEO

3. GLOB ECO Srl. - CEO

4. Network Srl Contacts - Commercial Director

5. ACMEI SOUTH Spa - Branch Manager

6. Polytechnic of Bari - Contact OF

7. The Cycloid - Holder

8. Congregation of the Sisters of Divine Providence - Opera Don UvaManaging director

9. Inspectorate General of Military Health - Ministry of DefenceDeputy Inspector General

10. Nomos Srl - CEO

11. Group Eco Liri Spa - Board Chairman

12. CONFIMPRESEITALIA - President

13. Co.S.I.La.M. - President

14. University of Cassino- Executive

15. Bank of Cassinate s.c.p.a. - Head of Marketing

The specifically analyzed non-homogeneity of the areas belonging to selected organizations enriches the considerations and reflections on the subject, highlighting different interpretations that however move towards one direction, which is the enhancement of creativity and human resources, with a convergence of views on the factors and conditions that favor its development. The target companies have a good consolidation on the market, with a presence for several years. They were witnesses of important changes occurred in the economic, social and political fields, that emphasize their 
systematic adaptability to reshape the emerging and changing needs, with a view to a continuous development. Creativity may have favored their ability to interpret the changes, anticipating the outcomes and preparing concrete and adequate answers.

\section{RESUlTS}

The subjects interviewed agree on the definition of H. Poincaré's creativity, as they regard it as particularly significant and relevant in their organizational reality. The search for the "new" that is also "useful" is favoured if "the value of human resources is recognized due weight at the value of human resources", considering their interests, passions and aspirations, having regard to their professional and cultural growth. For most managers the concept of creativity is closely linked to innovation, which is the implementation, that is their applicability and usefulness. The success of these companies over the years, seems to be due to their ability to constantly innovate products and / or processes, organization and staff skills, emphasizing the importance of the know-how and of the technology adopted and the continuously change brought about. Especially in times of severe crisis, creativity can enable companies not only to survive, but also to reinvent themselves in safeguarding knowledge and experience reinterpreted in the present moving towards the future. Despite the diversity of their core business, it is evident in the surveyed companies a "motivating vision" of the future of the organization that represents a challenge for its members and clear and shared objectives both inside and outside. The market and in particular the satisfaction of the needs of the customer/user, is an important stimulus for a creative management within the company, which among other things requires continuous adaptability to try new solutions when faced with differentiated demands.

It is evidently the business logic of the achievement of profit and therefore creativity is seen as an element promoting competitiveness in the market, but at the same time creating an attractive work environment.

The management of usual processes with new approaches can trigger creative dynamics especially in traditional sectors; creativity can emerge in the ability to solve complex problems with simple solutions. Creativity is the lifeblood, the fuel in the context of applied research; it is the humus for new experimentations through teamwork. The $7 \%$ of the sample believe that creativity, besides developing new connections, can question visions, tools, and even the individuals involved; moreover, it is not to underrated the contribution that in this direction can derive from the psychoanalysis of the creative power

The results relating to internal and external factors that can stimulate creativity and, conversely, those that can inhibit it, are graphically represented in order to highlight the different importance attributed to it by the managers interviewed.

The horizontal axis shows the variables indicated by the managers; on the ordinate axis the frequency (expressed in percentages of the answers), ie the number of managers who identified that variable as relevant.

\section{External factors that can foster creativity}

The graph below shows the importance given by the interviewed managers to the economic environment ("market", "emerging needs and others necessary to satisfy customers" through the "pursuit of quality" in the product / service offered, "at the technological and the political institutional environment in which the organization operates. An external environment based on "transparency in relations" and "simplification of procedures" can help to create a favorable atmosphere for the enterprises facilitating the creative process.

\section{Inner factors that can foster creativity}

The managers interviewed think that "the human resources development" is crucial in facilitating the creative potential and in creating a favourable climate within the labour organizations aimed at enhancing the value and the variety of skills, their empowerment through operational autonomy, the listening, the trust, the freedom of expression, the comparison and the interdisciplinary organization.

The "style of leadership" is crucial in this sense: in a democratic type of leadership, a management is open to discussion and workers's claims, promotes teamwork, curiosity and passion, protects creative people and the satisfaction of their needs of security and work satisfaction. It is important to favour 
the flexibility of the process and of individuals to adapt to the changes, overcoming habits, prejudices and closures; this is easier to achieve in an "organizational structure" that reduces functional divisions and hierarchies (13.3\% suggests a net organization). The interviewees highlighted the importance of "an inner motivation" in developing the creativity of human resources. The $26 \%$ believe it should be suitably balanced with an exogenous motivation. With time the latter can no longer be satisfying; work instead of love, passion and pleasure of their activities, as well as being rewarding, can reach professional goals and this is an important component perceived by the customer / user, with important implications for the productivity of the company. $40 \%$ consider the achievement of "corporate profits" a factor that can stimulate the search for creative solutions. The "organizational culture" is essential for sharing the values and mission of productive and organizational strategic choices; it can synthesize the variables above, especially if the group is coordinated and led by figures who have managerial skills aimed at capturing ideas and suggestions that can anticipate scenarios and future changes. These considerations are briefly expressed in the graph number 2 .

\section{Factors that can inhibit creativity}

The "autocratic leadership", countered and limited by its hierarchical exercise, is perceived as strongly inhibiting by the interviewees; followed by "lack of dialogue, discussion and collaboration among colleagues" (which can generate social climbing and abuse of power in trying to pursue goals for personal interests), the failure to share the company's mission" (with a lack of awareness of what is taking place within the organization ).

\section{Factors that can inhibit creativity}

The "autocratic leadership", countered and limited by the hierarchical exercise, is perceived as strongly inhibiting by the interviewees; followed by "lack of dialogue, discussion and collaboration among colleagues" (which can generate careerism and prevarication on the goals for personal interests), the failure in sharing the company mission (with a lack of awareness of what is taking place within the organization). The "rigidity of the rules", the complexity arising from "procedures and bureaucratic processes" and the "pressure exerted by stakeholders" complete, according to the vision of the managers surveyed, the set of variables that can oppose the flowering of creativity in organizations.

Advantages and criticalities that can result from a creative management of the organization according to the managers interviewed

The managers interviewed believe that creativity can promote the development of the organization by making it more competitive on the market, with the advantage of a greater advantage of the customer/client. This could lead to a climate of stimulating work aimed at giving impulse to improvement and innovation, cultural and personal development, with a special attention to the aspirations of individuals and a greater staff motivation (7\% of the subjects interviewed believe that this condition may help to reduce the rate of absenteeism), reduce the organizational stress, achieve greater efficiency and effectiveness through the development and increase of the productivity of human resources. Creativity can make individuals more resilient and promote wellbeing; it can stimulate the participation and a sense of belonging to the group. A generalized and uncontrolled creative approach can be risky for the company; it is therefore appropriate to verify its results and applicability. A lack of coordination, leading to organizational anarchy might occur and also to lower efficiency in the short term and a greater complexity in the management. Rejection may also be shown by those who have little inclination to change and resistance of the people in getting involved, not only with regard to economic interests and position, but also in terms of the ability to manage emotions and relationships. In certain cases creativity can lead to excessive exaltation of the individual to the damage of the group. The percentage expresses the number of managers who identified some relevant factors in the specified variables.

The internal resistance acts of the individual are perceived not as inhibiting a priori factors but as criticalities to be dealt with in the managing activity when a creative response in the human resource is requested. The subjects interviewed are in favor of the team work (provided it is compatible with the specific nature of the tasks that sometimes necessarily require individual performances and the heterogeneity of skills, a collaborative attitude but in a good mix with healthy competition, without leaving the pursuit of the common objective. They are willing to share ideas and experiences and in this sense a major role is played by internal communications in creating an environment favorable to 
the exchange of knowledge. When asked specifically if the mistakes can be shareable in an effort to generate new ideas and experiment with methods and alternative techniques, 60\% of managers interviewed responded that the error can become a time of growth and lead to important discoveries when it is audited by the group. The $33 \%$ of them believe that it is possible to learn from mistakes, even from the mistakes of vision and approach to knowledge and change. However, the $20 \%$ said that in businessapthere are areas such as Research, Development and Marketing where experimentation is more appropriate and less risky. A working group may be efficient and creative if skillfully led; the management has a strategic role. Brainstorming, adopted by $60 \%$ of respondents, is perceived as a moment of growth of the group and of the organization. $7 \%$ of the whole sample use the Techniques adopted by Edward De Bono while the $13 \%$ of them emphasized the importance of conducting "participatory meetings" in an informal atmosphere to stimulate the creative potential of employees, whose proposals might suggest creative approaches to solve problems. Benchmarking and Gaming are adopted by the $27 \%$ of the selected sample. There is a unanimous recognition of the importance of the training activity in general, which becomes an opportunity for discussion and dialogue, through the involvement of the entire workforce in an effort to develop new ideas and training strategies both for the individual and for the organization. Respondents agree that creativity can be improved by means of study and experience, and it may be that the personal component that gives added value to the basic skills is mainly due to the managerial and technical know-how used. The organizational contexts in which creativity techniques are not practiced are expected to be implemented in the future. The interviewees agree that creativity is a value shared by the organization and an essential part of the corporate culture. According to the $46 \%$ of the sample, creativity, while being positive in organizations, is more difficult to be applied in typically traditional contexts The lack of a systematic creative approach may hinder the creative flourishing within the organizational culture; it is therefore desirable a widespread and pervasive creativity, not episodic and limited to the imagination and the genius of a few individuals. Creativity can become a "model", a "style" and a "philosophy of life" of the organization; it may be its "leader" and DNA, according to an opinion shared by $40 \%$ of the sample investigated; it should therefore move in that direction. "Thinking outside the scheme" is important and $60 \%$ of respondents believe that it as much as the technical experts.

\section{DisCUSSION}

Studying creativity in collective and organizational contexts implies the analysis of many complex variables, in which the factors that can facilitate the creative process (such as the business climate, motivation) can in their turn become advantages, thus creating a profitable virtuous circle within the organization. The experience of creativity described by the managers highlights the importance of reaching a compromise, a meeting point between rationality and intuition, control and freedom to take action, defense of what already exists improved by new experiences. Although it has been underlined the difficulty to act "creatively" in some areas of the company, as it is more risky) and therefore the need to control the creative process, most managers perceive creativity as a usable capacity of all the staff of the firm. Therefore they do not seem to have a vision of it in terms of "a specialized activity" as pointed out by Gurteen, in line with the importance attributed to the development of human resources. It is just the exploitation of human resources that, by stimulating creativity, can trigger processes of improvement in individual performance $s$ for the benefit of well-being and efficiency of the organization. The companies surveyed reveal a proactive attitude of the management, a preference for active answers that provide anticipatory solutions to the complexity and changeability of the environment. Every answer reveals the need to work on organizational and motivational factors decisive in stimulating the creative potential of human resources. This highlights the fact that some theories of creativity have become part of the cultural heritage of many managers. In particular, managers agree with the idea of setting up a team work, the heterogeneity of skills, knowledge exchange, the importance of "intrinsic motivation" (agreeing with Teresa Amabile, from whom they differ only in relation to the concept of "competition". This author, in fact, believes that this component is destructive for creativity, while managers believe that it is right to make a mix of cooperation and healthy competition). The brainstorming is the most widely used and well known methodology in the organizational realities interviewed; other creativity techniques have not yet fully implemented in daily work. The analysis confirms the perception of managers favouring the organizational conditions can stimulate creative attitudes in human resources and also favour the development and well-being but we should deepen in this aspect in practical terms. From the analysis carried out it emerges the importance of managing with "attention" the human resources, and 
creativity, in this sense, could play an important role, together with the ordinary and traditional instruments of personnel administration. Creativity is considered by respondents as a key factor in fostering greater flexibility in the organization, with the aim of overcoming a static and hierarchical setting. The style of leadership has an important weight and a managerial participatory style is preferable as confirmed by the perception of the "autocratic style" as an inhibiting factor. The survey carried out, that is a "journey of discovery" in the daily life of managers, confirmed that the company is not an abstract entity, but is made by men. Creativity in its various manifestations (innovation with products and / or new services, adoption of more effective solutions, ideas aimed at solving or anticipating potential problems, etc.), comes and is necessarily generated by human resources. Cultivating that "creative potential" is, therefore, essential to lead the company, which is also "potentially creative", to innovation and expansion. Encouraging the creativity of the human resource means taking care of its "development" and recognize its human and professional "value". Through empowerment, autonomy and encouragement of the experimentation of "the new reality", the involvement in what besides being useful for the achievement of the objectives of the organization, makes it more passionate and motivating through the support of the working group, you can make sure that personal and business values can coexist and meet. This would imply, in general, a proper business climate and organizational well-being, generating optimism, trust, sharing of experience and knowledge and also energy and a proactive attitude towards the inside and the outside environments.

\section{Conclusions}

In each contribution received it was found the recognition of the importance of "the creative ability", and, in any case, there was a contextualization of creativity in every organizational reality. Listening and reading the contributions collected drive us to "live" these organizations, involving us in their development, in their world of strategic, economic and ethical values, in the vision and mission, in the diversity of business and organizational structures, but with the common belief that behind the diversity of economic activities, of the different markets on which they work, there are always men, who lead and coordinate other men in achieving a common goal, which is to satisfy the needs and expectations of other people, ie customers / users. The experience gained through this research proves the important role of the Manager, of the Human Resources and of their "creative management" in the evolutionary process toward the new and useful, that daily involved the business organization. Creativity requires a great change, in which the desire and the motivation of everyone to undertake this journey are essential, in the belief it would explore new ways to interpret and act the "daily business". Creativity can be perceived in the organizational structure, in the climate and in the working environment, in the culture, mission and history of the company and plays a strategic role in every functional area of the companies. Working hard on inner organizational dynamics, together with a positive impulse from external variables (market, political, economic and institutional contexts, technological input) and the use of "Creativity Techniques" can promote the "creative process", triggering a fruitful virtuous circle in the relationship among business, external environment and stakeholders. Successful organizations are the ones which can detect and "creatively" interpret the context in which they carry on their activity by developing their ability to adapt and shape themselves in front of constantly emerging drives and rapid changes; they are the ones that can easily be changed because they see "beyond" the commonplace, the already known, with curiosity, pragmatism and passion. In the companies surveyed, it unanimously emerges the recognition of the importance of the person, regarded as a work resource and as a customer / user recipient of the products / services offered. The sharing of values and mission of the company is essential, involving everyone in the achievement of the corporate objectives, to which the efforts and energies of each partner are directed. Besides, the proofs collected show the importance of the implementation of creativity in innovation in the companies, which serve as a driving force in the impulses and changes carried into the market in which they are operating. Continuous transformations, high level of competitiveness, number of competing actors evidence the existence of a turbulent context in the external environment necessarily requiring a dynamic attitude that drives to the search for differentiated solutions by activating a "creative process" on the offer, the processes, the internal organization and on the human resources management. Despite the favorable nature of the evidence detected, it is desirable to provide a wider dissemination of "creativity". An initial "creative technique" would be to use this word more often and make sure that it is more present in everyday life and in the business language. It is also appropriate to observe that the research carried out is confined to investigate the views of managers related to creativity. The study should be extended to test empirically how the concepts related to creativity are 


\section{Rosella Tomassoni et al.}

effectively put into practice. The inclusion of creativity techniques within traditional training, such as accountancy, business planning, marketing, communication and so on could stimulate a wider spread of creativity. Encouraging creativity means overcoming what is static, proceeding in an evolutionary perspective, in which the fundamental activities such as listening, having confidence and empathy, recognizing the value of the other persons, identifying areas for improvement, favouring the growth of skills and knowledge, having even recourse to a specific training that, starting from the individual, may involve the entire structure, in its concrete aspects (such as the layout and logistics) and also in its intangible ones (know-how, values, vision). Creativity consists in motivation and involvement regarding each individual but centered to the integration of actions that lead to the achievement of common objectives: the mission and development of the organization through the development of its human resources. "Creativity" may turn a person, an enterprise, a plan into an opportunity both for the individual subject and for firms.

\section{APPENDIX}
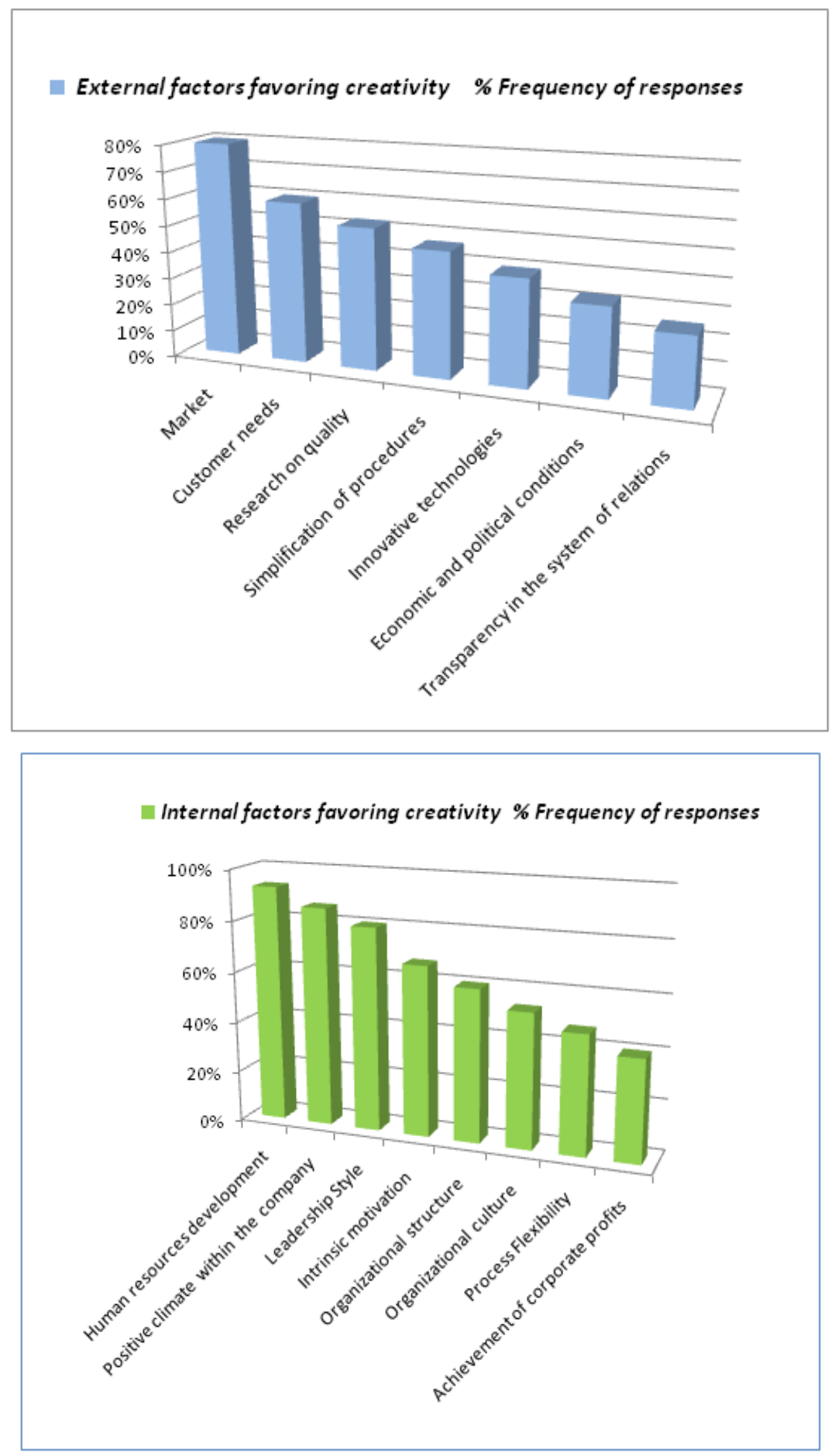


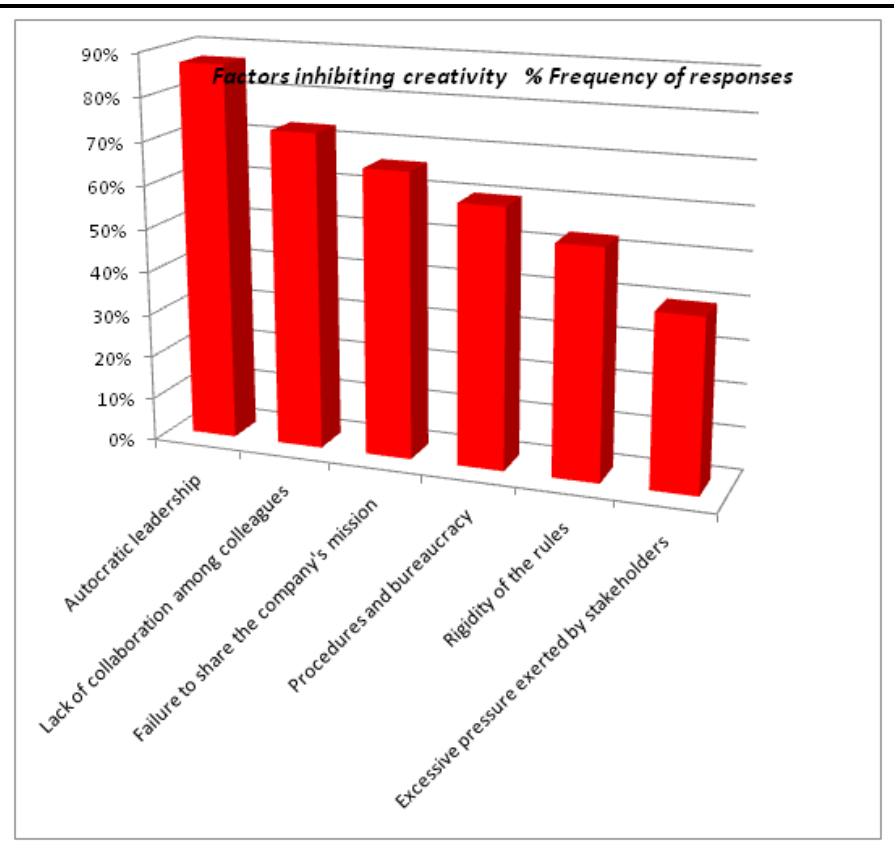

REFERENCES

Agnesa, M. Psicologia manageriale. La gestione strategica delle risorse umane. Limena (PD): Libreria Universitaria.it (2012).

Amabile, T. M. (1998, September - October). How to Kill Creativity. Harvard Business Review, 5, pp.76-87, (1998, September - October). DOI:http://dx.doi.org/10.4135/9781446213704

Bertone, V.Creatività aziendale. Metodi, tecniche e casi per valorizzare il potenziale creativo di manager e imprenditori.Milano, Franco Angeli, (2003).

Buzan, T., \& Buzan, B. The Mind Map Book: How to Use Radiant Thinking to Maximize Your Brain's Untapped Potential. New York,Plume, (1996).

De Bono, E. Sei cappelli per pensare. Milano, BUR Rizzoli, (2012).

De Bono, E. Il pensiero laterale. Milano,Rizzoli, (2000).

Florida, R. L'ascesa della nuova classe creativa: stili di vita, valori e professioni. Milano, Mondadori, (2003).

Gianandrea, F.R. Creatività for ever. 60 tecniche di gruppo per stimolare nuove idee e risolvere problemi. Milano, FrancoAngeli, (2009).

Goi, A. Professione Manager: Teoria e pratica della gestione strategica delle risorse umane. Milano,FrancoAngeli, (2014)

Goleman, D., Ray, M., \& Kaufman P.Lo spirito creativo. Milano, Rizzoli, (1999).

Gurteen, D. Knowledge, Creativity and Innovation. Journal of Kowledge Management, 2 (1), pp. 513. (1998, September). DOI:http://dx.doi.org/10.1108/13673279810800744.

Jaoui, H. Tutti innovatori!. Milano, Il Sole 24 Ore, (2003).

Jaoui, H., \& Dell'Aquila, I.L'intelligenza creativa. Bari, La Meridiana, (2008).

Joly, M. Idee che rendono....come trovarle: massimizzare la creatività industriale. Milano: FrancoAngeli, (1995).

Legrenzi, P.Creatività e innovazione. Bologna, Il Mulino, (2005),

Osborn, A. F. L'arte della creativity. Principi e procedure di creative problem-solving. Milano,FrancoAngeli, (2003).

Poincaré, J.H. Scienza e metodo. Torino, Einaudi, (1997).

Raudsepp, E. L'importanza di essere creativi: 50 giochi ed esercizi per rafforzare la creatività nella professione. Milano, FrancoAngeli, (1989).

Thompson, C. Libera la tua creatività: Tecniche e strategie di pensiero per generare idee sempre nuove e brillanti. Urgnano (BG), Alessio Roberti, (2013).

Varra, L. L'innovazione in azienda. Razionalità e creatività nei relativi processi decisionali e organizzativi. Lavis (TN), Cedam, (2012).

Vicari, S. La creatività nell'impresa. Tra caso e necessità. Milano, Etas Libri, (1998) 


\section{SITOGRAPHY}

www.exprivia.it

www.acmei.it

www.network-contacts.it

www.qnomos.it

www.globeco.info

www.confimpreseitalia.org

www.donuva.it

www.cicloide.it

http://dei.poliba.it

www.difesa.it

www.gruppoecolirispa.com

www.cosilam.it

www.unicas.it

www.bancapopolaredelcassinate.it

\section{AUTHORS' BIOGRAPHY}

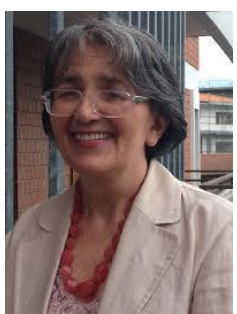

Rosella Tomassoni, Full Professor of General PsychologyatDepartment of Human, Social and HealthSciences, University of Cassino (Italy); Member of the Russian Academy of Human Sciences (Moscow). One of the nineElectedMembers of the Board of the ItalianCouncil of the AcademicPsychology. DeputyPresident of the Board of Directors at the University of Cassino and Southern Lazio. Coordinator of $\mathrm{PhD}$ Course in Institutions, Marketing and BehaviouralSciences and already Head of Department of Human and Social Sciencessince 2005 to 2012.

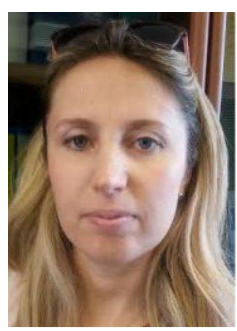

Eugenia Treglia, Researcher in General Psychologyat the University of Cassino and the Southern Lazio (Italy). Lecturer in Psychology of Art and Literature and in Psychology of Creativity. Psychologist and Psychotherapist with clinical and psychodynamicorientation. Shehaspublishedmany books and articles on general psychology, Psychology of Art and Literature and Creativity.

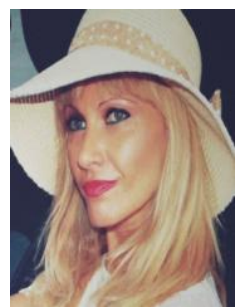

Silvia Perrella, Consultant and Corporate Trainer. Expert in startup processes and enterprise development, Human Resources Management and Techniques of Creativity. She worked at BIC Lazio ( Business Innovation Centre, public company), since 2001 to 2013, dealing with self-employment orientation, business planning and management of UE funds. Currently, she works as a freelance with universities and educational institutions, business associations, training and tourism promotion agencies, participating in local development initiatives, local marketing and dissemination of corporate culture. Teacher in training courses and workshops on the topic of professional skills and entrepreneurship. Tourism Economics teacher at Regional Training Agency, Puglia. 